\title{
Subfoveal choroidal thickness changes after intravitreal bevacizumab therapy for central serous chorioretinopathy
}

\author{
Alterações da espessura subfoveal coroide após terapia com bevacizumab para \\ coriorretinopatia serosa central
}

Cinan Ünlü ${ }^{1}$, Gurkan Erdogan ${ }^{1}$, Tugba Aydogan Gezginaslan ${ }^{1}$, Betul llkay Sezgin Akcay ${ }^{1}$, Esra Kardes ${ }^{1}$, Tahir Kansu Bozkurt $^{1}$

\begin{abstract}
Purpose: To evaluate subfoveal choroidal thickness (SFCT) changes after intravitreal bevacizumab (IVB) therapy for central serous chorioretinopathy (CSC) using enhanced depth imaging spectral-domain optical coherence tomography (EDI-OCT).

Methods: In this retrospective study, we assessed the medical records of patients with CSC who received IVB (IVB group) or who were observed without intervention (control group). SFCT was measured using EDI-OCT. The main outcome measure was the change in SFCT.

Results: Twenty-one eyes were included in the IVB group and 16 eyes were included in the control group. All patients showed resolution of neurosensory detachment and improvement in vision. In the IVB group, the mean SFCT was $315 \mu \mathrm{m}$ at baseline, which decreased to $296 \mu \mathrm{m}$ at the most recent visit. In the control group, the mean SFCT was $307 \mu \mathrm{m}$ at baseline, which decreased to $266 \mu \mathrm{m}$ at the most recent visit. Although there was a significant decrease in the mean SFCT for the control group, the decrease was not significant for the IVB group (41 vs $19 \mu \mathrm{m}, p=0.003$ vs $p=0.071$ ).

Conclusions: SFCT decreased in both groups with remission of the disease. However, the decrease was significantly greater in the control group. In terms of anatomic and functional outcomes, IVB injection is not promising.
\end{abstract}

Keywords: Intravitreal injection; Bevacizumab; Central serous chorioretinopathy; Choroid; Optical coherence tomography

\section{RESUMO}

Objetivo: Avaliar as alterações da espessura da coroide subfoveal (SFCT) após terapia com bevacizumab (IVB) para coriorretinopatia serosa central (CSC) usando tomografia de coerência óptica de domínio espectral com profundidade aprimorada (EDI-OCT).

Métodos: Neste estudo retrospectivo, foram avaliados prontuários de pacientes com CSC que receberam IVB (grupo IVB) ou que foram apenas observados, sem intervenção (grupo controle). SFCT foi medido por meio de EDI-OCT. O desfecho principal avaliado foi a mudança na SFCT.

Resultados: Houve 21 olhos no grupo IVB e 16 olhos no grupo de controle. Todos os pacientes apresentaram resolução de descolamento neurossensorial e melhora na visão. No grupo IVB, a SFCT media foi 315 um no início e diminuiu para 296 um na visita mais recente. No grupo controle, a SFCT média foi $307 \mu m$ no início e diminuiu para $266 \mu \mathrm{m}$ na visita mais recente. Embora tenha havido uma diminuição significativa na SFCT média para o grupo controle, a diminuição não foi significativa para o grupo IVB (41 $\mu$ m contra $19 \mu \mathrm{m}, \mathrm{p}=0.003$ vs $\mathrm{p}=0.071$ ).

Conclusões: A SFCT diminuiu em ambos os grupos após a remissão da doença. Contudo, a diminuição foi significativamente maior no grupo de controle. Em termos de resultados anatômicos e funcionais, a injeção de IVB não foi promissora.

Descritores: Injeções intravítreas; Bevacizumab; Coriorretinopatia serosa central; Coroide; Tomografia de coêrencia óptica

\section{INTRODUCTION}

Central serous chorioretinopathy (CSC) is an idiopathic condition characterized by the development of a well-circumscribed, serous detachment of the sensory retina in the posterior pole. Although the pathogenesis of CSC has been extensively studied, it still remains controversial(1-3). The primary pathology may involve dysfunction of the retina pigment epithelium (RPE) or choriocapillaris hyperpermeability or both. Gass postulated that choriocapillaris hyperpermeability was the cause of CSC. Later, studies using indocyanine green angiography (ICGA) showed multiple areas of choroidal vascular hyperpermeability, vascular dilatation, filling delay in the choroidal arteries and choriocapillaris, and punctate hyperfluorescent spots ${ }^{(4-8)}$. These angiographic findings strongly support the theory of Gass, which suggests that the primary pathology underlying CSC involves choroidal vascular changes. Recent studies using enhanced depth imaging spectral-domain optical coherence tomography (EDI-OCT) have showed that the choroid is very thick in patients with CSC, which might indicate the crucial role of the choroid in $\operatorname{CSC}^{(9-11)}$.

Although most cases with CSC may resolve spontaneously without any intervention, treatment may be required in chronic and recurrent cases and in acute cases who need prompt restoration of vision due to occupational or other needs. Several treatment options are now available, including pharmacological treatment with acetazolamide, nonsteroidal anti-inflammatory drugs, argon laser photocoagulation of the leaking site, and photodynamic therapy with verteporfin. It is well known that vascular endothelial growth factor (VEGF) is related to vascular permeability ${ }^{(12)}$. Anti-VEGF agents may reduce choroidal hyperpermeability. Recently, several reports have demonstrated acceptable outcomes after intravitreal anti-VEGF agent (ranibizumab and bevacizumab) injection in patients with $\operatorname{CSC}^{(12-18)}$.

Conventional OCT devices have limited ability for choroidal imaging due to low penetration and high light scattering at the level of

Submitted for publication: January 27, 2016

Opthalmology Department, Ümraniye Training and Research Hospital, İstanbul, Turkey.

Funding: No specific financial support was available for this study.

Disclosure of potential conflicts of interest: None of the authors have any potential conflicts of interest to disclose.

Corresponding author: Cihan Ünlü. Bengisu evleri sitesi D2/2 Bengisu cad. Așağı Dudullu mah. Ümraniye, ìstanbul, Turkey - E-mail: drcihanunlu@yahoo.com

Approved by the following research ethics committee: Ümraniye Training and Research Hospital, istanbul, Turkey. 
the RPE. Spaide introduced the EDI-OCT technique, which improved imaging of the choroid. Since this landmark study, an increasing number of investigators have studied choroidal thickness in several diseases of the eye $\mathrm{e}^{(9,19-21)}$. In this study, we aimed to evaluate the choroidal thickness changes after intravitreal bevacizumab (IVB) injection in patients with CSC and compare the results with those of control patients who did not receive any treatment for CSC. This finding may help to elucidate the pathophysiology of CSC.

\section{METHODS}

This study followed the tenets of the Declaration of Helsinki. This retrospective comparative study was approved by the local ethics committee (Ümraniye Training and Research Hospital, İstanbul, Turkey). Written informed consent, explaining all potential risks and possible benefits of the IVB injection and the off-label nature of this therapy, was obtained from all patients who received the IVB injection.

The charts of patients who were diagnosed with unilateral CSC were reviewed. The diagnosis of CSC was established by the presence of serous macular detachment on dilated fundus examination, fluorescein leakage on fluorescein angiography (FA), and corresponding subretinal fluid accumulation as evidenced by OCT. Each of the patients had a history of comprehensive ocular examinations, including best-corrected visual acuity (BCVA) on a Snellen chart, intraocular pressure measurement, biomicroscopic examination, dilated retinal examination, and OCT examinations. All eyes were examined with the RTVue-100 OCT device (Optovue Inc., Fremont, CA, USA). The charts of the patients were excluded from this study if the patients had a history of previous chorioretinal disease, history of intraocular surgery, previous photodynamic therapy, or intravitreal anti-VEGF therapy, glaucoma, high myopia with a refractive error $<-6.0$, or other eye diseases that could compromise visual acuity. Patients with systemic diseases that could have affected the choroidal thickness such as diabetes mellitus or malignant hypertension were also excluded. Patients who were included in this study were followed up for at least 3 months.

Patients who were treated with an intravitreal injection of $0.05 \mathrm{ml}$ $\left(1.25 \mathrm{mg}\right.$ ) of bevacizumab (Avastin ${ }^{\circledR}$ ) were grouped as the IVB group, and patients who were only observed without any treatment were grouped as the control group. We administered IVB injections to the acute patients with CSC who were eager to receive this treatment due to occupational needs or excessive discomfort because of the decreased vision. IVB injection was performed through the pars plana into the vitreous cavity under strict aseptic conditions. Eyes were injected less than 2 weeks after diagnosis in our clinic. The control group was observed without any treatment.

Subfoveal choroidal thickness (SFCT) measurements were obtained by the EDI-OCT technique previously described by Spaide ${ }^{(18)}$. SFCT was defined as the vertical distance from the hyperreflective line of Bruch's membrane to the inner surface of the observed sclera under the center of the fovea. Baseline and final SFCT measurements were obtained for the IVB and control groups. Final SFCT measurements for comparison between the groups were performed at the final visit at the end of the follow-up period.

At all follow-up visits, patients were examined with slit-lamp examination and OCT. FA was performed at the discretion of the examiner. The BCVA was obtained in all patients. Re-injection was performed in some of the patients if sustained, and reaccumulated subretinal fluid was associated with moderate-to-severe vision loss. Re-injections were performed at least 2 months following the primary injection.

\section{Statistical analysis}

Statistical analyses were performed using Number Cruncher Statistical System 2007 and Power Analysis and Sample Size 2008 Statistical Software (Utah, USA). Visual acuity measurements were converted into the logarithm of the minimum angle of resolution
(logMAR) for analysis. The primary outcome measures were changes in SFCT and BCVA. Descriptive statistics methods such as the mean, standard deviation, and median were used to analyze the data. Normally distributed data were analyzed using Student's t-test between groups and paired sample t-tests within each group. Non-normally distributed data were analyzed using the Mann-Whitney U-test between groups and the Wilcoxon signed-rank test within each group. Fisher's exact test was used to compare percentages. For all tests, $p<0.05$ was considered to be statistically significant.

\section{RESULTS}

The study included 37 eyes of 37 patients. The mean age of the patients was $44.7 \pm 9.4$ years (range, $24-64$ years). Twenty-six patients (70\%) were male, and 11 patients (30\%) were female. The mean follow-up time was $9.4 \pm 8.4$ months (range, 3-30 months). There were 21 patients in the IVB group and 16 patients in the control group. The demographic characteristics of the groups are summarized in table 1. No significant differences were detected between the two groups.

The mean SFCT and the mean BCVA at baseline and the final visits for both groups are summarized in table 2. Figures 1 and 2 show a

Table 1. Demographic characteristics of the groups

\begin{tabular}{lccc}
\hline & $\begin{array}{c}\text { IVB }(\boldsymbol{n}=\mathbf{2 1}) \\
\text { mean } \pm \text { SD }\end{array}$ & $\begin{array}{c}\text { Control }(\boldsymbol{n}=\mathbf{1 6}) \\
\text { mean } \pm \text { SD }\end{array}$ & p value \\
\hline Patient age (years) & $46.2 \pm 8.2$ & $42.70 \pm 10.60$ & ${ }^{\mathrm{a}} 0.269$ \\
Duration of CSC episode (weeks) & $11.3 \pm 5.3$ & $10.94 \pm 6.02$ & ${ }^{\mathrm{b}} 0.540$ \\
Follow-up time (months) (median) & $10.2 \pm 9.5(6.0)$ & $8.40 \pm 7.00(3.5)$ & ${ }^{\mathrm{b}} 0.404$ \\
\hline & $\boldsymbol{n}(\mathbf{\%})$ & $\boldsymbol{n}(\mathbf{\%})$ & \\
\hline Gender & & & \\
Female & $4(19.0 \%)$ & $7(43.8 \%)$ & \\
Male & $17(81.0 \%)$ & $9(56.2 \%)$ & \\
\hline
\end{tabular}

$\mathrm{CSC}=$ central serous chorioretinopathy; IVB= intravitreal bevacizumab.

${ }^{a}=$ Student's $t$-test $;{ }^{b}=$ Mann-Whitney $U$-test ${ }^{c}=$ Fisher's exact test.

Table 2. The mean subfoveal choroidal thickness and the mean BCVA at baseline and at the final visit for both groups

\begin{tabular}{|c|c|c|c|}
\hline & $\begin{array}{c}\text { IVB }(n=21) \\
\text { mean } \pm \text { SD (median) }\end{array}$ & $\begin{array}{c}\text { Control }(n=16) \\
\text { mean } \pm \text { SD (median) }\end{array}$ & $p$ value \\
\hline \multicolumn{4}{|l|}{ BCVA } \\
\hline Baseline & $0.49 \pm 0.23(0.50)$ & $0.45 \pm 0.21(0.5)$ & a 0.709 \\
\hline Final & $0.70 \pm 0.26(0.70)$ & $0.86 \pm 0.27(1.0)$ & ${ }^{\mathrm{a}} 0.021^{*}$ \\
\hline${ }^{b} p$ & $0.001^{* *}$ & $0.001^{* *}$ & \\
\hline Difference & $0.22 \pm 0.21(0.20)$ & $0.41 \pm 0.31(0.5)$ & $0.046^{*}$ \\
\hline \multicolumn{4}{|l|}{ logMAR BCVA } \\
\hline Baseline & $0.37 \pm 0.24(0.30)$ & $0.39 \pm 0.22(0.3)$ & a 0.709 \\
\hline Final & $0.19 \pm 0.21(0.15)$ & $0.10 \pm 0.19(0.0)$ & ${ }^{\mathrm{a}} 0.021^{*}$ \\
\hline${ }^{b} p$ & $0.001^{* *}$ & $0.001^{* *}$ & \\
\hline Difference & $0.17 \pm 0.21(0.11)$ & $0.29 \pm 0.27(0.3)$ & $\mathrm{a} 0.110$ \\
\hline \multicolumn{4}{|l|}{ SFCT } \\
\hline Baseline & $315.05 \pm 56.96(304.0)$ & $306.69 \pm 50.64(303.5)$ & ${ }^{c} 0.646$ \\
\hline Final & $295.86 \pm 52.95(287.0)$ & $265.69 \pm 40.90(254.5)$ & ${ }^{\circ} 0.067$ \\
\hline${ }^{d} p$ & 0.071 & $0.003^{* *}$ & \\
\hline Difference & $19.19 \pm 46.10(11.0)$ & $41.00 \pm 46.92(35.0)$ & $\mathrm{a} 0.290$ \\
\hline
\end{tabular}

$\mathrm{BCVA}=$ best-corrected visual acuity; IVB= intravitreal bevacizumab; log MAR= logarithm of the minimum angle of resolution; SFCT= subfoveal choroidal thickness.

${ }^{*}=p<0.05 ;{ }^{* *}=p<0.01$.

${ }^{a}=$ Mann-Whitney $U$-test; ${ }^{b}=$ Wilcoxon signed-rank test; ${ }^{c}=$ Student's $t$-test; ${ }^{d}=$ Paired sample test. 


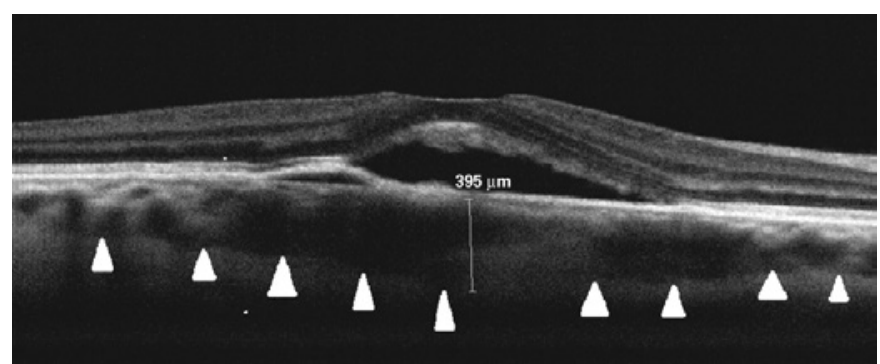

Figure 1. Baseline enhanced depth imaging spectral-domain optical coherence tomography imaging of a patient with acute central serous chorioretinopathy. The subfoveal choroidal thickness was $395 \mu \mathrm{m}$.

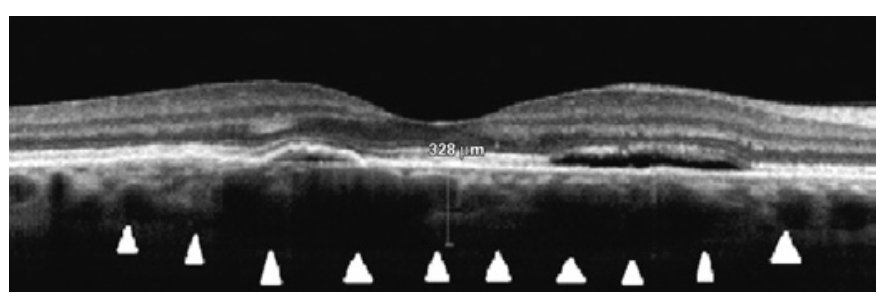

Figure 2. Final enhanced depth imaging spectral-domain optical coherence tomography imaging of a patient with acute central serous chorioretinopathy. The subfoveal choroidal thickness was $328 \mu \mathrm{m}$.

representative case at the baseline and final visits, respectively. All patients showed complete resolution of neurosensory detachment and improvement in vision at the final visit after the follow-up period. In the IVB group, the mean SFCT was $315 \pm 57 \mu \mathrm{m}$ at the baseline visit, which decreased to $296 \pm 53 \mu \mathrm{m}$ at the final visit after a mean follow-up period of 10.2 months. In the control group, the mean SFCT was $307 \pm 51 \mu \mathrm{m}$ at the baseline visit, which decreased to $266 \pm$ $41 \mu \mathrm{m}$ at the final visit after a mean follow-up period of 8.4 months. The mean SFCT at the baseline and final visits did not significantly differ between the groups. Although there was a significant decrease in the mean SFCT for the control group, no significant decrease was found for the IVB group (41 vs $19 \mu \mathrm{m}, p=0.003$ vs $p=0.071$ ). The mean BCVA levels in the IVB group at the baseline and final visits were 0.49 (logMAR 0.37) and 0.70 (logMAR 0.19), respectively. In contrast, the mean BCVA levels in the control group at the baseline and final visits were 0.45 (logMAR 0.39) and 0.86 (logMAR 0.10), respectively. The mean BCVA at the baseline visit was similar for both groups, and the mean BCVA increased significantly in both groups $(p=0.001)$. However, the increase in the mean BCVA was significantly greater for the control group $(0.41$; logMAR 0.29) than for the IVB group (0.22; $\log M A R$ 0.17; $p<0.05$ for BCVA), and the mean final BCVA of the control group was significantly greater than that of the IVB group [0.86 (logMAR 0.10) vs 0.70 (logMAR $0.19 p<0.05]$.

Twenty-eight patients (76\%) had total and nine patients (24\%) had near-total resolution of subretinal fluid at the end of the acute CSC episode; only 12 of 16 patients (75\%) in the observation group had complete resolution, and only 16 of 21 patients (76\%) in the IVB group had complete resolution. The resolution rates were similar in both groups, and re-injection was performed on five patients in the IVB group ( $n=21)$. No treatment complications were observed during the follow-up period.

\section{DISCUSSION}

No established treatment modalities exist for CSC. Various treatments, including topical or systemic carbonic anhydrase inhibitors, laser photocoagulation to the leaking site, photodynamic therapy with verteporfin, and intravitreal injection of anti-VEGF agents, have been applied with variable success rates. In this study, we aimed to demonstrate the effect of IVB therapy on the choroid, which plays a vital role in the pathogenesis of CSC.

There have been many theories concerning the pathogenesis of CSC. RPE dysfunction or defect has been blamed in the development of serous retinal detachment in CSC $^{(22,23)}$. Gass proposed that CSC was the result of choroidal vascular hyperpermeability ${ }^{(1)}$. Later studies using ICGA supported the theory of Gass and demonstrated evidence of hyperpermeability from the choriocapillaries ${ }^{(24,25)}$. Increased hydrostatic pressure from choroidal vascular hyperpermeability may cause leaks from the level of the RPE and subsequent serous retinal detachment ${ }^{(25)}$. Based on this knowledge, choroidal vascular abnormalities seem to play a key role in the pathogenesis of CSC as the underlying mechanism. Using EDI-OCT, Imamura et al., demonstrated the presence of a thick choroid in patients with $\operatorname{CSC}^{(9)}$. Increased choroidal thickness in patients with unilateral CSC has been shown not only in the affected eyes but also in the unaffected fellow eyes ${ }^{(10)}$. In the present study, the baseline mean SFCTs were $315 \pm 57 \mu \mathrm{m}$ in the IVB group and $307 \pm 51 \mu \mathrm{m}$ in the control group, which are greater than that of the normal population [unpublished data: we had previously evaluated 412 eyes of 206 normal Turkish subjects with a mean age of 45 years and found a mean SFCT of $254.4 \pm$ $43.1 \mu \mathrm{m}$ (range, 122-426 $\mu \mathrm{m}$ )], which supports the presence of a thick choroid in patients with CSC. This finding is consistent with the results from a previous study by Kim et al., in which the SFCT of normal individuals was found to be $266 \pm 55 \mu \mathrm{m}^{(10)}$. In the present study, after a mean follow-up period of 10 months, the mean SFCT decreased to $296 \pm 53$ and $266 \pm 41 \mu \mathrm{m}$ in the IVB and control groups, respectively, and the mean BCVA levels increased to 0.70 and 0.86 in the IVB and control groups, respectively. According to these results, better visual acuity is associated with thinner SFCT. This decrease can be interpreted as an approach toward the normal physiological state for SFCT, which was associated with better visual acuity in the control group.

Bevacizumab is a full-length monoclonal antibody that selectively bonds with VEGF. Since 2005, it has been used in ophthalmology to treat various conditions, including neovascular age-related macular degeneration, diabetic macular edema, retinal vein occlusions, and neovascular glaucoma ${ }^{(26)}$. Variable outcomes have been reported on the use of bevacizumab in $\operatorname{CSC}^{(13,16)}$, and the mechanism of action of bevacizumab in CSC is unknown. Choroidal ischemia may cause an increase in the concentration of VEGF and subsequent choroidal hyperpermeability, which results in a thickened choroid in CSC. At this point, some benefits of an anti-VEGF agent may be proposed on the basis of choroidal ischemia and hyperpermeability as the pathogenesis of CSC(12-14). However, no studies have demonstrated an increased level of VEGF in CSC until now. Conversely, Lim et al., reported no significant difference in the VEGF levels in the aqueous humor of patients with CSC compared with a control group ${ }^{(27)}$. In addition, the optimal dosage of IVB for CSC has not been formally evaluated. We have used a dosage of $1.25 \mathrm{mg}$ in $0.05 \mathrm{ml}$, which is the typical dosage of bevacizumab used in other well-studied disease states ${ }^{(28-29)}$. Furthermore, there are still some controversies about the nature of the disease. It is not yet understood whether the resolution of subretinal fluid is due to IVB or the natural history of the disease. In the present study, the effect of bevacizumab injection was not promising compared with observation in terms of the functional and structural outcomes. This finding supports the literature, which indicates no beneficial effect of anti-VEGF agents in CSC ${ }^{(16)}$.

Since the introduction of EDI-OCT by Spaide et al., this technique has been used by many authors to evaluate the choroidal thickness in various diseases and conditions such as age-related macular degeneration, high myopia, and $\operatorname{CSC}^{(9,18)}$. Increased choroidal thickness was demonstrated in both eyes of patients with unilateral active $\mathrm{CSC}^{(10)}$, and changes in choroidal thickness have been shown to be closely related to choroidal vasculature ${ }^{(30)}$. However, it remains unclear 
whether or not choroidal thickening on OCT might represent the disease activity in CSC. In the present study, decreased SFCT was associated with better visual acuity in both groups. Further studies with more patients and a more objective measurement method for the choroidal thickness may reveal a relationship between choroidal topographic changes and disease activity.

This study had some limitations, including its retrospective nature, small sample size, and manual measurement of SFCT. Because our OCT device does not include software for the automated measurement of SFCT, we manually measured the distance from the hyperreflective line of Bruch's membrane to the inner surface of the observed sclera under the fovea.

In the present study, we demonstrated that IVB injection in CSC is not superior to observation in terms of the anatomic and functional outcomes, and that SFCT decreased with remission of the disease. Further investigation is needed to demonstrate the role of the choroid in CSC pathophysiology and the place of IVB as a useful treatment option.

\section{REFERENCES}

1. Gass JD. Pathogenesis of disciform detachment of neuroepithelium. Am J Ophthalmol. 1967;63(3):1-139.

2. Spaide RF, Goldbaum M, Wong DW, Tang KC, lida T. Serous detachment of the retina. Retina. 2003;23(6):820-46; quiz 895-6.

3. Marmor MF. New hypotheses on the pathogenesis and treatment of serous retinal detachment. Graefes Arch Clin Exp Ophthalmol. 1988;226(6):548-52.

4. Prünte $C$. Indocyanine green angiographic findings in central serous chorioretinopathy. Int Ophthalmol. 1995:19(2):77-82.

5. Prünte C, Flammer J. Choroidal capillary and venous congestion in central serous chorioretinopathy. Am J Ophthalmol. 1996;121(1):26-34.

6. lida T, Kishi S, Hagimura N, Shimizu K. Persistent and bilateral choroidal vascular abnormalities in central serous chorioretinopathy. Retina 1999;19(6):508-12.

7. Kitaya N, Nagaoka T, Hikichi T, Sugawara R, Fukui K, Ishiko S, et al. Features of abnormal choroidal circulation in central serous chorioretinopathy. Br J Ophthalmol. 2003;87(6): 709-12.

8. Tsujikawa A, Ojima Y, Yamashiro K, Ooto S, Tamura H, Nakagawa S, et al. Punctate hyperfluorescent spots associated with central serous chorioretinopathy as seen on indocyanine green angiography. Retina. 2010;30(5):801-9.

9. Imamura Y, Fujiwara T, Margolis R, Spaide RF. Enhanced depth imaging optical coherence tomography of the choroid in central serous chorioretinopathy. Retina. 2009; 29(10):1469-73. Comment in: Retina. 2010;30(8):1320-1; author reply 1321-2.

10. Kim YT, Kang SW, Bai KH. Choroidal thickness in both eyes of patients with unilaterally active central serous chorioretinopathy. Eye (Lond). 2011;25(12):1635-40.

11. Jirarattanasopa P, Ooto S, Tsujikawa A, Yamashiro K, Hangai M, Hirata M, et al. Assessment of macular choroidal thickness by optical coherence tomography and angiographic changes in central serous chorioretinopathy. Ophthalmology. 2012;119(8): 1666-78.

12. Inoue M, Kadonosono K, Watanabe Y, Kobayashi S, Yamane S, Arakawa A. Results of one-year follow-up examinations after intravitreal bevacizumab administration for chronic central serous chorioretinopathy. Ophthalmologica. 2011;225(1):37-40.
13. Artunay O, Yuzbasioglu E, Rasier R, Sengul A, Bahcecioglu H. Intravitreal bevacizumab in treatment of idiopathic persistent central serous chorioretinopathy: a prospective, controlled clinical study. Curr Eye Res. 2010;35(2):91-8.

14. Lim SJ, Roh MI, Kwon OW. Intravitreal bevacizumab injection for central serous chorioretinopathy. Retina. 2010;30(1):100-6. Comment in: Retina. 2010;30(8):1322-3; author reply 1323; Retina. 2011;31(1):198-9; author reply 199. Retina. 2010;30(8):1323-24; author reply 1324 .

15. Torres-Soriano ME, García-Aguirre G, Kon-Jara V, Ustariz-Gonzáles O, Abraham-Marín $\mathrm{M}$, Ober MD, et al. A pilot study of intravitreal bevacizumab for the treatment of central serous chorioretinopathy (case reports). Graefes Arch Clin Exp Ophthalmol. 2008; 246(9):1235-9.

16. Lim JW, Ryu SJ, Shin MC. The effect of intravitreal bevacizumab in patients with acute central serous chorioretinopathy. Korean J Ophthalmol. 2010:24(3):155-8.

17. Seong HK, Bae JH, Kim ES, Han JR, Nam WH, Kim HK. Intravitreal bevacizumab to treat acute central serous chorioretinopathy: short-term effect. Ophthalmologica. 2009; 223(5):343-7.

18. Spaide RF, Koizumi H, Pozzoni MC. Enhanced depth imaging spectral-domain optical coherence tomography. Am J Ophthalmol. 2008;146(4):496-500. Erratum in: Am J Ophthalmol. 2009:148(2):325.

19. Reibaldi M, Boscia F, Avitabile T, Uva MG, Russo V, Zagari M, et al. Enhanced depth imaging optical coherence tomography of the choroid in idiopathic macular hole: A cross-sectional prospective study. Am J Ophthalmol. 2011;151(1):112-7. Comment in: Am J Ophthalmol. 2011;151(3):560-1; author reply 561.

20. Chung SE, Kang SW, Lee JH, Kim YT. Choroidal thickness in polypoidal choroidal vasculopathy and exudative age-related macular degeneration. Ophthalmology. 2011; 118(5):840-5

21. Maruko I, lida T, Sugano Y, Oyamada H, Sekiryu T, Fujiwara T, et al. Subfoveal choroidal thickness after treatment of Vogt-Koyanagi-Harada disease. Retina. 2011;31(3):510-7.

22. Maruko I, lida T, Sugano Y, Ojima A, Ogasawara M, Spaide RF. Subfoveal choroidal thickness after treatment of central serous chorioretinopathy. Ophthalmology. 2010; 117(9):1792-9.

23. Bae SH, Heo JW, Kim C, Kim TW, Lee JY, Song SJ, et al. A randomized pilot study of low-fluence photodynamic therapy versus intravitreal ranibizumab for chronic central serous chorioretinopathy. Am J Ophthalmol. 2011;152(5):784-92.

24. Scheider A, Nasemann JE, Lund OE. Fluorescein and indocyanine green angiographies of central serous choroidopathy by scanning laser ophthalmoscopy. Am J Ophthalmol. 1993;115(1):50-6

25. Guyer DR, Yannuzzi LA, Slakter JS, Sorenson JA, Hope-Ross M, Orlock DR. Digital indocyanine-green videoangiography of occult choroidal neovascularization. Ophthalmology. 1994;101(10):1727-35; discussion 1735-7.

26. Stewart MW. The expanding role of vascular endothelial growth factor inhibitors in ophthalmology. Mayo Clin Proc. 2012;87(1):77-88.

27. Lim JW, Kim MU, Shin MC. Aqueous humor and plasma levels of vascular endothelial growth factor and interleukin-8 in patients with central serous chorioretinopathy. Retina. 2010;30(9):1465-71.

28. Avery RL, Pieramici DJ, Rabena MD, Castellarin AA, Nasir MA, Giust MJ. Intravitreal bevacizumab (Avastin) for neovascular age-related macular degeneration. Ophthalmology. 2006;113(3):363-72. Comment in: Ophthalmology. 2007;114(2):400; author reply 400-1.

29. Spaide RF, Laud K, Fine HF, Klancnik JM Jr, Meyerle CB, Yannuzzi LA, et al. Intravitreal bevacizumab treatment of choroidal neovascularization secondary to age-related macular degeneration. Retina. 2006:26(4):383-90.

30. Vance SK, Imamura Y, Freund KB. The effects of sildenafil citrate on choroidal thickness as determined by enhanced depth imaging optical coherence tomography. Retina. 2011:31(2):332-5. 